\title{
Hilar Area of the Left Lung
}

National Cancer Institute

\section{Source}

National Cancer Institute. Hilar Area of the Left Lung. NCI Thesaurus. Code C49253.

The area associated with the hilum of the left lung. 